\title{
Estudo comparativo experimental de compósito bioativo de matriz polimérica para aplicação em cirurgia plástica ocular na substituição tecidual
}

\author{
Experimental comparative study ofbioactivecomposite with polymeric matrix for \\ applications to oculoplastic surgery for tissue replacement
}

\author{
Valênio Pérez França ${ }^{1}$ \\ Ana Rosa Pimentel de Figueiredo ${ }^{2}$ \\ Anilton César Vasconcelos ${ }^{3}$ \\ Rodrigo Lambert Oréfice ${ }^{4}$
}

\begin{tabular}{|c|}
\hline RESUMO \\
\hline 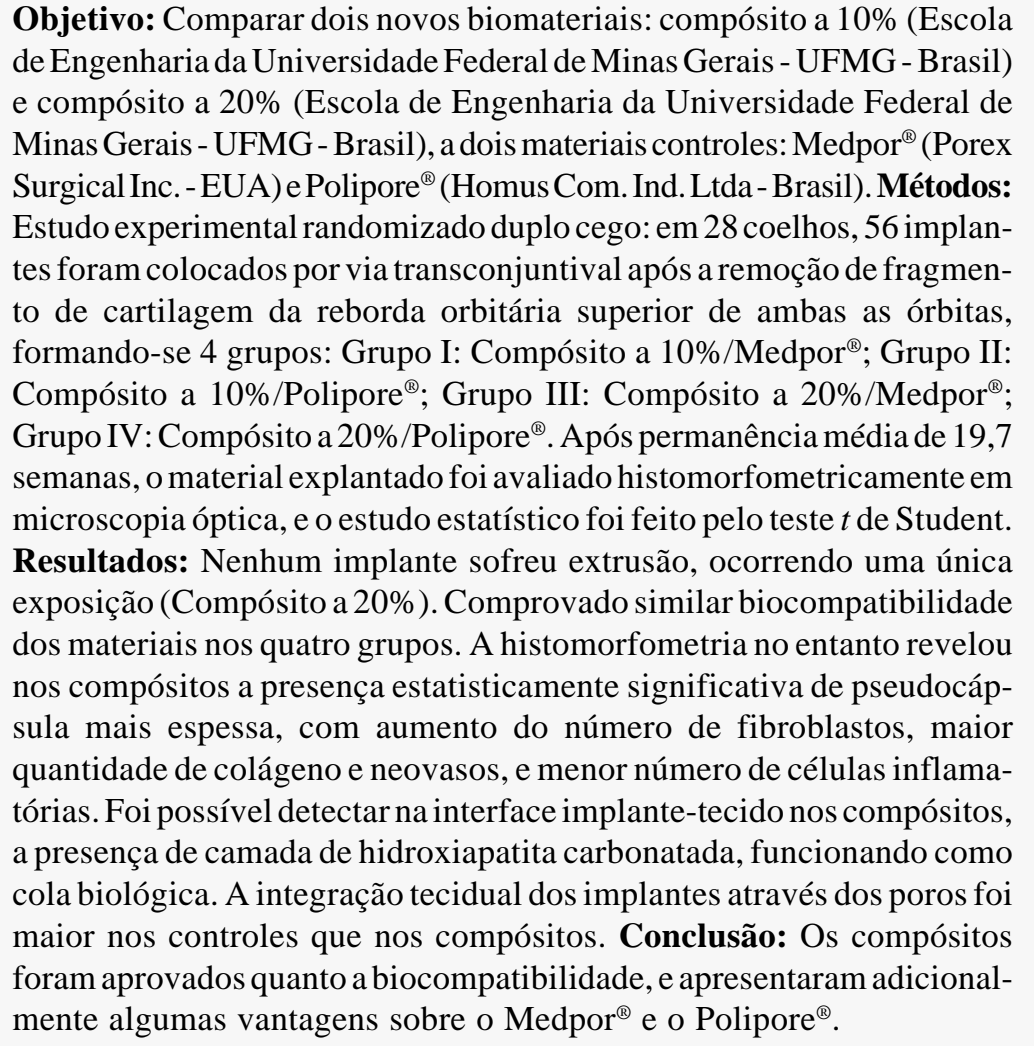 \\
\hline
\end{tabular}

Descritores: Cirurgia plástica/tendências; Resinas compostas/uso terapêutico; Materiais biocompatíveis/uso terapêutico; Próteses e implantes; Inflamação; Adesivos teciduais; Ensaio Controlado Aleatório [Tipo de Publicação]; Coelhos/cirurgia; Estudo comparativo

\section{INTRODUCÃO}

Várias técnicas cirúrgicas são empregadas em plástica ocular a fim de se obter um resultado que devolva a funcionalidade a uma estrutura afetada, preservando, ao mesmo tempo, a estética. Para reparar essas estruturas, freqüentemente utilizamos os implantes. Uma grande variedade de materiais naturais e sintéticos são utilizados na confecção desses implantes, e empregados para alcançar os objetivos e resultados cirúrgicos planejados: são os chamados biomateriais. 
O biomaterial pode ser definido como um implante que é colocado em contato com o tecido vivo com o objetivo de recompor alguma parte lesada, ou auxiliar na sua recuperação. Pode agir de modo contínuo ou intermitente, entrando em contato com fluidos corpóreos, mesmo que localizado fora do $\operatorname{corpo}^{(1)}$.

O conceito de que todo e qualquer material que fosse totalmente inerte no organismo seria biocompatível, foi reconsiderado a partir do momento em que se percebeu que qualquer tipo de material sempre desencadeia uma resposta do tecido hospedeiro, representada pela formação de cápsula fibrosa ao redor do implante. Além disso, observou-se que, para certas aplicações, havia necessidade de alguma forma de interação entre o tecido hospedeiro e o material, que em determinadas situações seria mais importante para a satisfatória atuação do implante ${ }^{(2)}$

Quanto a sua natureza, os biomateriais podem ser catalogados em:

- naturais: (ex: osso, córnea, colágeno, hidroxiapatita coralínica);

- sintéticos (polietileno, politetrafluoretilenos, acrilatos, silicones, malhas de polímeros, vidros bioativos, adesivos tissulares).

Atualmente na área médica são empregados mais de 40 tipos de biomateriais em mais de 50 implantes diversos ${ }^{(3-4)}$. Alguns exemplos desta classe de materiais ${ }^{(5)}$ estão na figura 1.

Sintéticos ou naturais, biológicos ou não, todo o biomaterial para implantação têm que exibir a capacidade de ser bem tolerado pelo organismo hospedeiro. A exceção do material autólogo, todos os outros provocam, em maior ou menor grau, resposta imunológica reacional. A pesquisa de material biocompatível busca encontrar um substituto do tecido humano que não desencadeie distúrbio imuno-histoquímico nocivo, e também interaja favoravelmente com o tecido hospedeiro, aproximando-se ao máximo das qualidades exigidas pela função específica a ser exercida por aquele órgão ou tecido reparado.

A vantagem dos materiais sintéticos sobre os biológicos está na maior facilidade de obtenção, melhor programação e reprodutibilidade dos resultados, maior segurança da assepsia, possibilidade de desenho e produção personalizada do implante, e rapidez de fabricação. Comparado ao material biológico autólogo, o biomaterial sintético ou natural tem como

\begin{tabular}{|c|c|}
\hline Silicone e derivados & $\begin{array}{l}\text { Bioplastique, Silicone injetável, em } \\
\text { folha, em esponja, em placas e em gel }\end{array}$ \\
\hline Politetrafluoretileno & Gore-Tex, Protoplast I e II, Teflon \\
\hline Polietileno de alta densidade & Medpor $^{\circledast}$, Polipore $^{\circledast}$ \\
\hline Malha de polímeros & $\begin{array}{l}\text { Dacron=Mersilene, Dexon, Prolene, } \\
\text { Supramid, Vicryl }\end{array}$ \\
\hline Vidro bioativo & $\begin{array}{l}\text { Vidro bioativo=Bioglass }{ }^{\circledR} \text {, Vidro } \\
\text { ionômero }\end{array}$ \\
\hline Adesivo tissular & Cianoacrilato \\
\hline Acrílicos & HTR polímero, Metacrilato de metila \\
\hline \multicolumn{2}{|c|}{ Fonte: Ousterhout DK, Stelnick EJ, 1996. p.183 ${ }^{(5)}$} \\
\hline
\end{tabular}

Figura 1 - Quadro com exemplos de materiais sintéticos utilizados como biomateriais em implantes desvantagem a possibilidade de rejeição e custo de produção mais elevado. Quanto à rejeição, pesquisas estão favorecendo a produção de compostos cada vez melhor tolerados pelo organismo, com futuro promissor ${ }^{(3)}$. Quanto aos custos, poderiam ser reduzidos se houvesse uma universalização no emprego do biomaterial, e que um único material pudesse ter a capacidade de ser utilizado em várias e diferentes funções na área médica.

Dentre os materiais sintéticos existe uma classe de biomaterial pouco difundido em nosso meio, que são os compósitos ${ }^{(3)}$.

Os compósitos passaram a ser conhecidos a partir do trabalho pioneiro de Bonfield et al. em 1981 como uma alternativa válida para uso em medicina como biomateriais ${ }^{(6)}$.

Os compósitos são definidos como materiais formados por dois ou mais constituintes, com distintas composições, estruturas e propriedades, separados por uma interface. Esse conceito muito amplo pode incluir um grande número de materiais que usualmente não são chamados de compósitos, como as ligas metálicas. Embora uma definição exata não seja comumente empregada, considera-se compósito um sistema constituído de materiais que têm suas propriedades individuais drasticamente afetadas pela introdução de quantidades insignificantes de um segundo constituinte ${ }^{(7)}$.

O compósito bioativo envolve geralmente a presença de uma matriz polimérica - que confere adequadas propriedades mecânicas, físicas e químicas ao implante - e uma fase bioativa como por exemplo, uma biocerâmica, que assegura biocompatibilidade adequada com interação favorável implantehospedeiro $^{(8)}$.

\section{OBJETIVO}

O objetivo deste trabalho foi experimentar in vivo (coelho adulto) um novo biomaterial desenvolvido pela Escola de Engenharia da UFMG: Compósito de matriz polimérica de polietileno poroso com uma fase bioativa de biocerâmica em duas frações volumétricas diferentes, $10 \%$ e $20 \%$, comparando-os, clínica e histomorfometricamente, a dois implantes controles de polietileno já conhecidos - Medpor ${ }^{\circledR}(\text { EUA })^{(9)}$ e Polipore $^{\circledR}(\text { Brasil })^{(10)}$.

\section{MÉTODOS}

O compósito bioativo foi produzido a partir de uma mistura de partículas de polietileno de alta densidade, vidro bioativo (composição molar: 46,1\% de $\mathrm{SiO}_{2} ; 24,4 \%$ de $\mathrm{Na}_{2} \mathrm{O} ; 26,9 \%$ de $\mathrm{CaO}$ e $2,6 \%$ de $\mathrm{P}_{2} \mathrm{O}_{5}$ ) nas proporções de $10 \%$ e $20 \%$, e pó de agente expansor azodicarbonamida a $0,33 \%$ e submetido a testes em fevereiro de 2002, no Departamento de Engenharia Metalúrgica e de Materiais da Escola de Engenharia da UFMG, tendo sido realizados ensaios de picnometria em água, espectroscopia de infravermelho, termogravimetria, análise calorimétrica exploratória, microscopia eletrônica de varredura 
(MEV), análise de raios-X por dispersão de energia (EDS), ensaios mecânicos para avaliação de resistência à tração e porosimetria de mercúrio; também foi realizado teste in vitro, em solução simuladora de fluido corpóreo $(\mathrm{SBF})^{(11)}$.

Nesse estudo duplo cego randomizado foram utilizados 28 coelhos (O. cuniculus) machos da raça Neozelandesa branca com 4 meses de idade, com peso médio de 2,06 quilogramas, formando-se quatro grupos:

Grupo I: sete animais com o par Compósito a 10\%/Medpor ${ }^{\circledR}$. Grupo II: sete animais com o par Compósito a 10\%/Polipore ${ }^{\circledR}$. Grupo III: sete animais com o par Compósito a 20\%/Medpor ${ }^{\circledR}$. Grupo IV: sete animais com o par Compósito a 20\%/Polipore ${ }^{\circledR}$.

Local de implantação: reborda orbitária superior de ambos os lados, $1 \mathrm{~cm}$ lateralmente ao ângulo interno da rima palpebral (Figura 2), em nicho cirúrgico confeccionado após remoção de cartilagem por via transconjuntival com mesmas dimensões do implante.

Número total de implantes: 56.

Dimensão dos implantes: $3 \mathrm{~mm}$ (espessura) X $6,5 \mathrm{~mm}$ (comprimento) X 5,4 mm (largura).

Esterilização dos implantes: óxido de etileno.

Anestesia: intramuscular, com mistura de xilazina (3 a $5 \mathrm{mg} / \mathrm{kg}$ de peso) e ketamina ( $35 \mathrm{a} 45 \mathrm{mg} / \mathrm{kg}$ de peso).

Tempo de permanência: de 106 a 153 dias, com média de 138 dias ou 19,7 semanas ( $75 \%$ dos implantes).

\section{Caracterização clínica}

Avaliações semanais quanto aos parâmetros abaixo:

a) Clínicos: comportamento fisiológico dos animais;

b) Ectoscopia: alteração de relevo e contorno da pálpebra superior;

c) Palpação: presença do implante, imobilidade e/ou permanência do implante no nicho cirúrgico.

\section{Caracterização microscópica}

\section{Histomorfometria:}

Baseado em trabalho com metodologia similar ${ }^{(12)}$, após inclusão em parafina os cortes histológicos de 5 micrômetros de espessura foram corados em HE e tricrômio de Masson, e de cada corte foram capturadas imagens em microscopia óptica (objetiva de 40X e ocular de 10X), abrangendo 10 campos da interface - área de contato entre o implante e o tecido hospedeiro - e quatro campos do tecido dentro dos poros. Em cada um dos 4 grupos, os implantes pareados foram comparativamente analisados, totalizando por grupo 140 campos na interface (10 campos X 7 animais X 2 implantes) e 56 campos dentro dos poros (4 campos X 7 animais $\mathrm{X} 2$ implantes).

As imagens foram capturadas por uma câmera (JVC/TK 1270 - Color Vídeo Câmera, Germany) a partir de um microscópio (Zeiss Axiolab, Alemanha) acoplado a um captador de imagens (Frame Grabber - MiroMOVIE PRO, Alemanha) e analisadas no analisador de imagens digitalizadas KS 300 (2.0) Kontron Eletronik do Departamento de Patologia Geral do Instituto de Ciências Biológicas da UFMG.
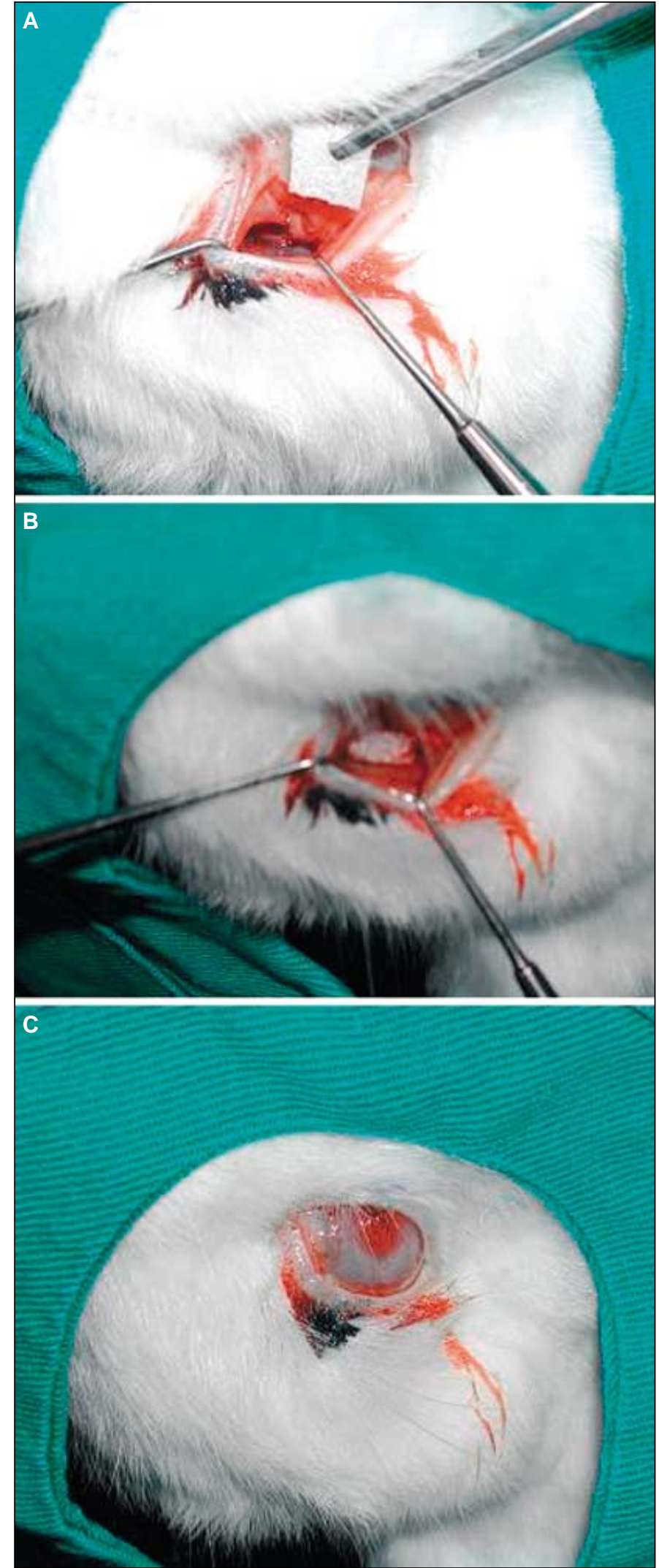

Figura 2 - Procedimento cirúrgico de colocação do implante. A: Exposição do nicho cirúrgico confeccionado pela retirada de fragmento da reborda orbitária cartilaginosa. B: Implante já posicionado dentro do nicho. C: Incisão cirúrgica fechada sem necessidade de pontos 
Parâmetros histomorfométricos analisados:

1) Identificação e contagem do número de macrófagos.

2) Identificação e contagem do número de fibroblastos.

3) Quantificação da heterogeneidade dos neovasos.

4) Medida da área dos neovasos.

5) Medida do diâmetro dos neovasos.

6) Medida da espessura média da pseudocápsula em torno do implante: média de três medidas, sendo uma central no local mais espesso da pseudocápsula, e duas laterais, à direita e à esquerda, distantes 200 micrômetros da medida central.

7) Quantificação da área ocupada pela neoformação de colágeno: nos cortes corados por tricrômio de Masson, onde o tecido pesquisado se cora em azul.

\section{MEV e EDS:}

Alguns blocos explantados de amostras de compósitos foram ainda submetidos a análises micrográficas sob MEV e EDS.

Análise estatística dos 4 grupos: teste $t$ de Student para amostras pareadas. Foram considerados significantes os valores de $\mathrm{p}<0,05$. Não realizado teste não paramétrico de Kruskal-Wallis porque a distribuição dos dados demonstrou normalidade.

\section{RESULTADOS}

\section{Caracterização clínica}

Todos os 28 animais mantiveram um padrão de comportamento normal e saudável, alimentando-se bem e com atividades fisiológicas normais.

Não houve extrusão de nenhum dos 56 implantes, porém houve exposição parcial de um Compósito a $20 \%$.

O contorno palpebral e o relevo da região se mantiveram sem alteração ou sinal de qualquer deformidade durante todo o período do experimento.

Dos 56 implantes de Compósito, 36 (64,3\%) se encontravam completamente aderidos aos planos teciduais profundos, e os outros $20(35,7 \%)$ estavam móveis; desses implantes, $54,1 \%$ foram encontrados dentro do nicho cirúrgico original, e em $(19,6 \%)$ houve migração parcial ou total $(26,5 \%)$ para os tecidos da pálpebra (Figura 3).

\section{Caracterização microscópica}

Os resultados da histomorfometria do tecido da interface, conforme o nível de significância estatística, estão apresentados na tabela 1. Apesar da ocorrência de menor integração dos compósitos em relação aos controles, a histomorfometria do tecido de dentro dos poros mostrou perfeita similaridade ao da interface.

(MEV): presença de tecido colonizando os poros dos implantes - Compósitos e controles; avaliado a morfologia dos poros nos compósitos (Figura 4).

(EDS): confirmada nos compósitos, a precipitação de cálcio e fósforo na interface implante-tecido, forte indício de presença de hidroxiapatita carbonatada (Figura 4).

\section{DISCUSSÃO}

O objetivo principal em produzir compósitos é o de combinar diferentes materiais para se obter um único implante com propriedades superiores às dos componentes unitários ${ }^{(13)}$.

Nesse aspecto, os compósitos parecem levar vantagem sobre outros materiais, já que teoricamente permitiriam, em

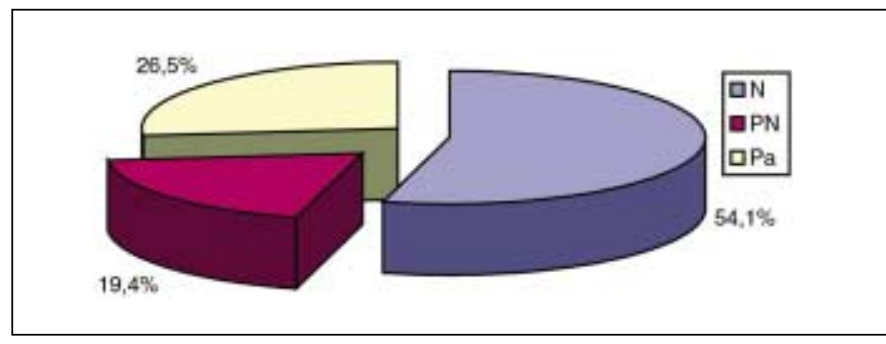

Figura 3 - Gráfico de setor mostrando em termos percentuais a localização topográfica dos implantes. $\mathrm{N}=$ implante no nicho cirúrgico original; $\mathrm{PN}=$ implante que migrou parcialmente para fora do nicho, estando parte na pálpebra e parte ainda no nicho; $\mathrm{Pa}=$ implante que migrou completamente para fora do nicho cirúrgico, se encontrando dentro dos tecidos da pálpebra

\begin{tabular}{|c|c|c|c|c|}
\hline \multirow[b]{2}{*}{$\begin{array}{l}\text { Parâmetros } \\
\text { morfométricos } \\
\text { (interface) }\end{array}$} & \multicolumn{4}{|c|}{ p = Nível de significância } \\
\hline & $\begin{array}{c}\text { Grupo I } \\
\text { Compósito } 10 \% \\
\text { X Medpor }\end{array}$ & $\begin{array}{c}\text { Grupo II } \\
\text { Compósito } 10 \% \\
\text { X Polipore }{ }^{\circledR}\end{array}$ & $\begin{array}{c}\text { Grupo III } \\
\text { Compósito } 20 \% \\
\text { X Medpor }\end{array}$ & $\begin{array}{c}\text { Grupo IV } \\
\text { Compósito } 20 \% \\
\text { X Polipore }{ }^{\circledR}\end{array}$ \\
\hline Espessura da pseudocápsula & $<0,0001^{*}$ (Comp. 10\%) & 0,0038* (Comp. 10\%) & 0,9338 (Comp. 20\%) & 0,0294* (Comp. 20\%) \\
\hline Número de macrófagos & $0,0494^{*}$ (Med) & 0,5656 (Poli) & $0,0409^{*}$ (Med) & 0,4763 (Comp. 20\%) \\
\hline Número de fibroblastos & 0,0095* (Comp. 10\%) & 0,3503 (Comp. 10\%) & 0,2039 (Comp. 20\%) & 0,4912 (Poli) \\
\hline $\begin{array}{l}\text { Heterogeneidade e } \\
\text { diâmetro dos vasos }\end{array}$ & 0,0200* (Comp. 10\%) & 0,0164* (Comp. 10\%) & 0,4320 (Comp. 20\%) & $<0,0001^{*}$ (Comp. 20\%) \\
\hline Área dos vasos & 0,2906 (Comp. 10\%) & 0,0031* (Comp. 10\%) & 0,2375 (Comp. 20\%) & $0,0147^{*}$ (Comp. 20\%) \\
\hline Área de colágeno & 0,0085* (Comp. 10\%) & 0,0006* (Comp. 10\%) & 0,3310 (Comp. 20\%) & 0,0101* (Comp. 20\%) \\
\hline
\end{tabular}




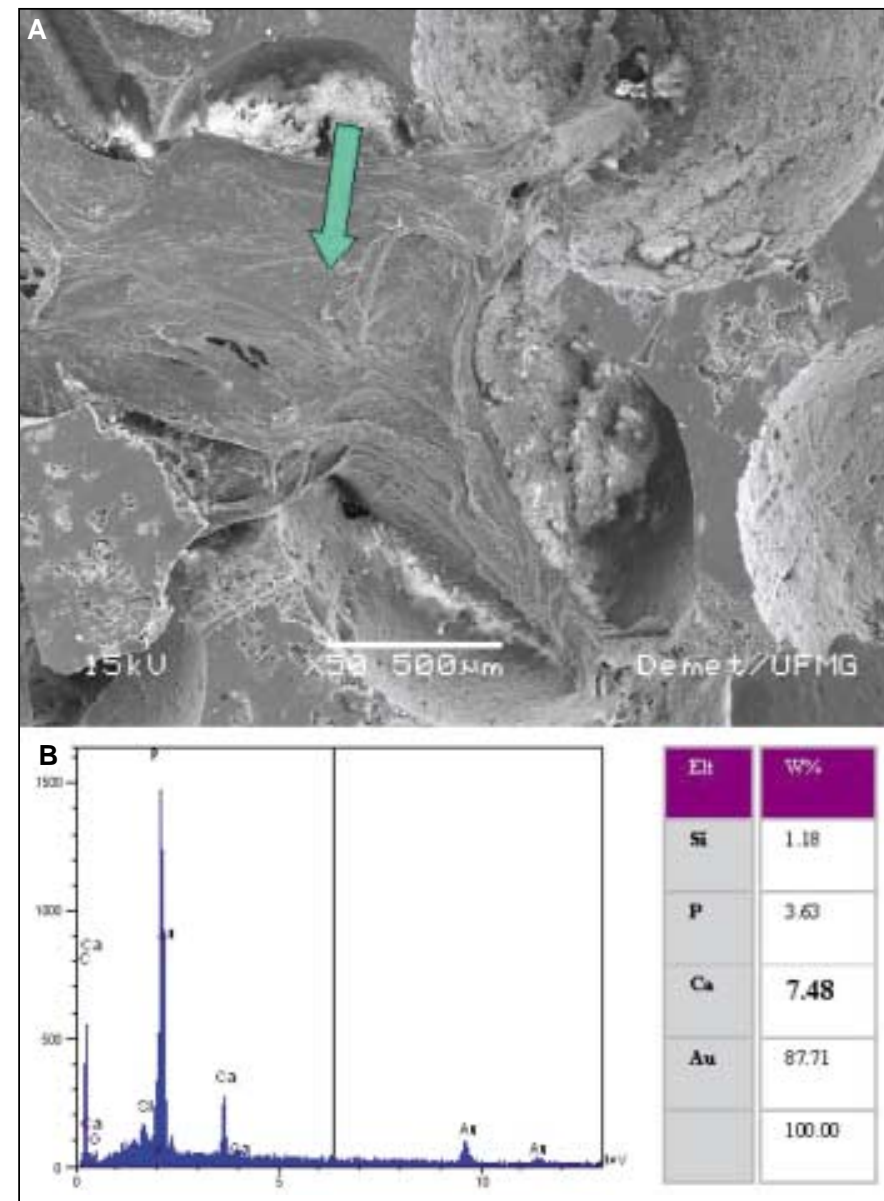

Fonte: Laboratório de Ciência e Engenharia de Materiais da Escola de Engenharia Metalúrgica e de Minas da UFMG

Figura 4 - A: Micrografia por MEV de uma amostra explantada de Compósito a $20 \%$ (objetiva $50 X$ ). Nota-se a morfologia dos poros do material com suas interconexões; a seta aponta para um vigoroso tecido de colonização, avancando para dentro dos poros. A superfície interna dos poros apresenta-se rugosa, sinal de interação química do Compósito como meio orgânico. B: Espectro por EDS desta mesma amostra, tomada na interface do material com o tecido, onde se observa a presenca de picos de Ca e $\mathbf{P}$ (fosfato de cálcio) característicos de fase bioativa, com provável precipitação de hidroxiapatita carbonatada. A tabela apresentada na figura é a representação numérica do perfil gráfico mostrado em B

problemas distintos, a utilização de um mesmo material. Os vários componentes do compósito, com suas diferentes especificidades, se misturados em proporções adequadas, podem alcançar os distintos objetivos almejados, simplesmente mudando-se a proporção de seus integrantes na mistura, realçando ou inibindo essa ou aquela propriedade.

Ainda em termos de biomateriais, uma análise da estrutura dos tecidos que constituem o corpo humano permite inferir que os mesmos são tipicamente compósitos ${ }^{(14)}$.

O osso natural é um microcompósito no qual uma reunião de pequenas partículas de apatita está efetivamente sendo reforçada por fibras colágenas ${ }^{(15)}$.

Assim é de se esperar que a substituição de tecidos vivos por materiais sintéticos esteja ligada ao desenvolvimento de compósitos especiais, capazes de reproduzir as propriedades dos tecidos humanos. Compósitos de matriz polimérica se encaixam bem nesse tipo de proposição, apresentando propriedades modeláveis através da alteração dos parâmetros do sistema. Esses parâmetros compreendem a fração volumétrica dos componentes (proporção dos componentes do material na mistura), tipo de polímero que irá constituir a matriz, tipo e morfologia dos agentes de reforço (fibra versus partículas). Para cada função especifica, características específicas podem ser otimizadas, preenchendo as necessidades do tecido a ser substituído.

Ao contrário de outro estudo ${ }^{(16)}$, aonde se utilizou a via de acesso transcutânea, neste trabalho utilizou-se acesso transconjuntival, por ser direto, facilitando o ato operatório. $\mathrm{O}$ procedimento foi rápido, apresentando duração media de sete minutos.

Com a metodologia de colocar o implante-controle e o implante-experimental em um mesmo animal, conseguiu-se minimizar os fatores individuais que poderiam interferir no estudo comparativo ${ }^{(17-18)}$.

A ausência de extrusão dos 28 implantes de compósitos, com somente exposição de um implante, mostrou a ótima biocompatibilidade do material pesquisado.

Em relação ao tempo de permanência dos implantes $(19,7$ semanas), outros experimentos com o mesmo objetivo, comprovaram ser este tempo adequado, ocorrendo completa integração do implante em quatro semanas ${ }^{(18-19)}$.

Não houve diferença estatisticamente significativa na avaliação clínica dos grupos quanto à alteração de contorno e relevo das pálpebras no local dos implantes, ou a mobilidade e permanência dos implantes no nicho cirúrgico. Apesar de grande mobilidade da região palpebral, somente $26,8 \%$ dos implantes migrou totalmente do local do nicho cirúrgico, índice menor que um estudo semelhante ${ }^{(20)}$, onde a migração ocorreu em $75 \%$ dos implantes. Esse fato pode ser atribuído à adequação do nicho cirúrgico, e, os compósitos, apresentarem camada de hidroxiapatita carbonatada (Figura 4). Esta camada, descrita na literatura ${ }^{(21)}$, atrai o colágeno, mucopolisacárides e glicoproteínas para a superfície do implante, formando uma interface orgânica-inorgânica que atua como uma verdadeira cola biológica entre o implante, o osso e os tecidos moles circunvizinhos. Essa cola química extremamente forte e estável é característica da atividade do componente bioativo (biocerâmica) do compósito e seria uma das maiores vantagens desse implante sobre os controles de polietileno (Medpor ${ }^{\circledR}$ e Polipore ${ }^{\circledR}$, pois proporciona, além do habitual mecanismo de adesão mecânica, fornecido pela colonização tecidual dos poros do material, como também associa uma adesão química, mais resistente que a mecânica (Figura 5) ${ }^{(22)}$.

A menor integração tecidual dos compósitos em relação aos controles, foi atribuído a inadequação morfológica dos poros, cuja interconectividade estreita impediu maior progressão do tecido em neoformação.

Analisando e discutindo os resultados da tabela 1, expres- 


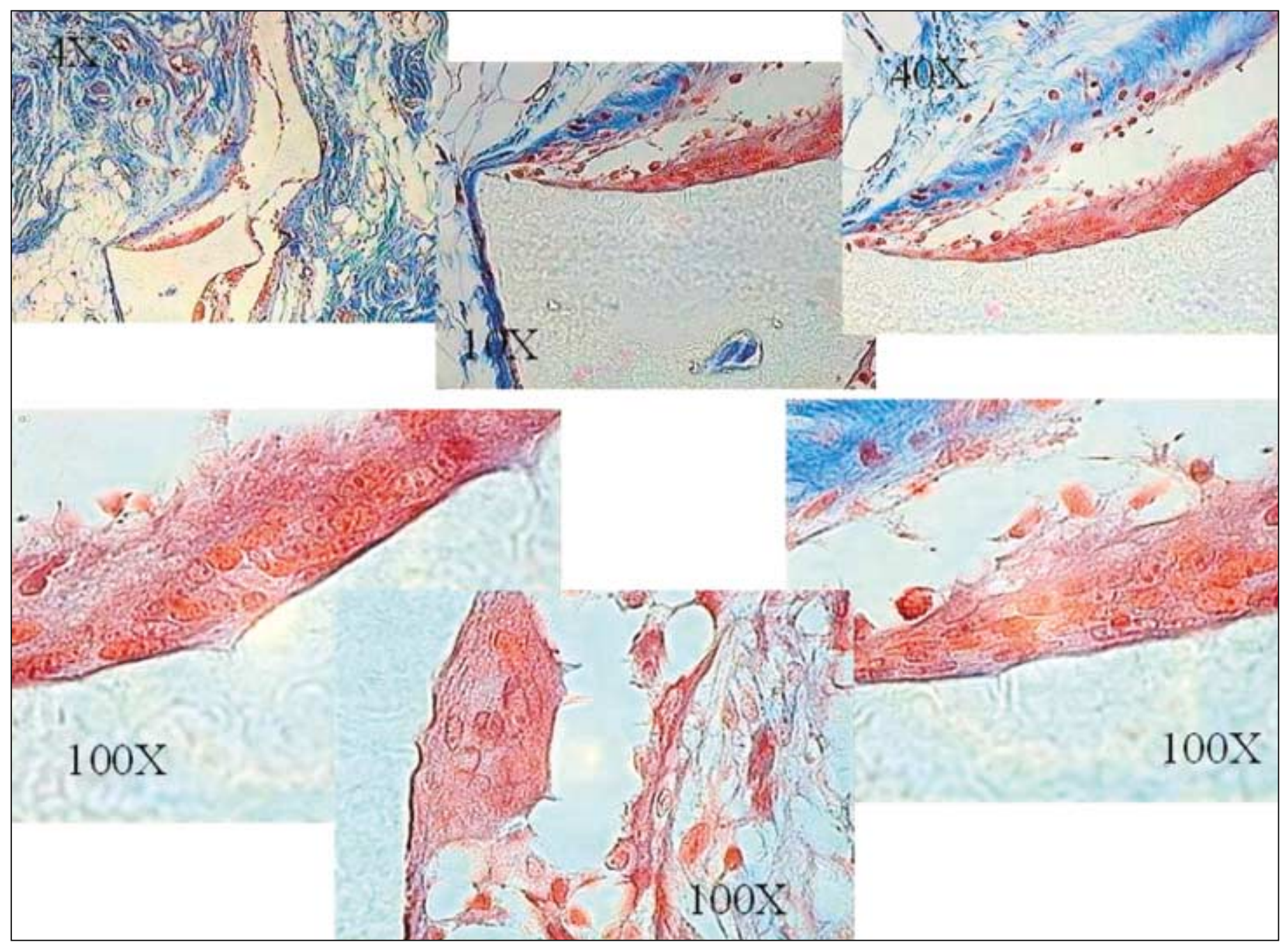

Figura 5 - Lâmina de Compósito bioativo a 20\% corada em tricrômio de Masson (objetiva de 10X e 100X), mostrando na interface material-tecido a firme adesão dos tecidos à superfície do implante, provavelmente decorrente da precipitação de hidroxiapatita carbonatada, que funcionou como uma cola biológica. Nota-se que o material ao se desgarrar levou com ele o tecido, que rasgou em sua intimidade e não na interface, como seria de se esperar caso fosse outro o biomaterial

sos em nível de significância, com relação à avaliação histomorfométrica da interface nos 4 grupos pode se afirmar que:

Grupo I: (Compósito a 10\% X Medpor ${ }^{\circledR}$ )

Em todos os parâmetros o compósito a $10 \%$ apresentou maior índice, à exceção do número de macrófagos, presentes em maior número no Medpor ${ }^{\circledR}(\mathrm{p}=0,0494)$. Nos itens espessura de pseudocápsula, fibroblastos, área de colágeno, heterogeneidade e diâmetro dos vasos, a diferença foi estatisticamente significante $(\mathrm{p}<0,05)$. Estes dados demonstram que o Compósito desenvolveu maior interatividade com o tecido hospedeiro, caracterizado por pseudocápsula mais espessa, com maior quantidade de neovasos, fibroblastos e de colágeno, no entanto, sem desencadear maior reação inflamatória, o que foi caracterizado por um menor número de macrófagos.

Grupo II: (Compósito a 10\% X Polipore $^{\circledR}$ )

Neste grupo os resultados foram semelhantes aos apresentados no Grupo I, mantendo uma grande interatividade com o tecido, com menor número de células inflamatórias. No entanto, chama a atenção a neoangiogênese, que no Compósito se mostrou significativamente acima da ocorrida no controle Polipore ${ }^{\circledR}$.

Grupo III: (Compósito a 20\% X Medpor ${ }^{\circledR}$ )

O Compósito a $20 \%$ apresentou resultado semelhante ao Compósito a $10 \%$, mas sem significância estatística (p>0,05), à exceção do número de macrófagos, maior no Medpor ${ }^{\circledR}$ $(\mathrm{p}=0,0409)$.

Grupo IV: (Compósito a 20\% X Polipore ${ }^{\circledR}$ )

O Compósito a $20 \%$ também apresentou interatividade maior com o tecido hospedeiro, com neoformação vascular acentuada. A exceção foi a presença de menor número de macrófagos e maior de fibroblastos no Polipore ${ }^{\circledR}$, ambos no entanto sem significância estatística.

Dessa maneira, encontramos nos compósitos uma pseudocápsula mais espessa, com mais colágeno, maior número de fibroblastos e neovasos, observação esperada de um material bioativo, mostrando maior interatividade com o tecido hospedei- 
ro. Salientamos como fator positivo mais relevante que a pseudocápsula nos compósitos apresentou processo inflamatório significativamente menor que a dos controles, mostrando maior biocompatibilidade, melhor qualidade do tecido de adesão e proporcionando também maior fixação mecânica do implante.

\section{CONCLUSÃO}

Os compósitos produzidos pelo Departamento de Engenharia Metalúrgica e de Materiais da Escola de Engenharia da UFMG demonstraram excelente biocompatibilidade, similar aos controles (Medpor ${ }^{\circledR}$ e Polipore ${ }^{\circledR}$ ). Em muitos aspectos apresentaram vantagens sobre estes, como maior interatividade com o tecido hospedeiro e menor reação inflamatória. Corroborando a literatura, pôde ser comprovado nos compósitos a precipitação de camada com elevado índice de íons cálcio e fósforo na interface do implante com o tecido, sugestivo da presença de hidroxiapatita carbonatada. Os compósitos foram colonizados em menor grau que os controles, recomendando ser revista a morfologia dos seus poros.

\section{ABSTRACT}

Purpose: To compare two new biomaterials: Composite $10 \%$ (Engineering School - Universidade Federal de Minas Gerais UFMG - Brazil) and Composite 20\% (Engineering School - Universidade Federal de Minas Gerais - UFMG - Brazil), with two similar materials as control: Medpor ${ }^{\mathrm{TM}}$ (Porex Surgical Inc. USA) e Polipore ${ }^{\mathrm{TM}}$ (Homus Com. Ind. Ltda - BRASIL). Methods: In vivo randomized experimental double blind study: a transconjunctival approach was performed in both cartilaginous superior orbital walls of 28 rabbits for 56 implants divided into 4 groups: GI: Composite 10\%/Medpor ${ }^{\mathrm{TM}}$; GII: Composite $10 \% /$ Polipore $^{\mathrm{TM}}$; GIII: Composite 20\%/Medpor ${ }^{\mathrm{TM}}$; GIV: Composite $20 \% /$ Polipore $^{\mathrm{TM}}$. The mean rate for implant time of permanence was 19.7 weeks. The Student's $t$ test was used for statistical analysis. Results: Revealed similar biocompatibility of all materials and none of the implants was extruded; one Composite $20 \%$ had partial exposure. Histomorphometry showed a greater bioactivity of the composites with significantly thicker fibrous encapsulation, with more collagen and fibroblasts, exuberant angiogenesis, and a lower inflammatory cell mean compared to controls. The presence of precipitation of a hydroxycarbonate apatite layer, which acts as an implant-tissue bond was confirmed. Composites presented a smaller tissular invasion index of the pores compared to controls. Conclusions: The composites showed a good biocompatibility and some additional advantage over the Medpor ${ }^{\mathrm{TM}}$ and Polipore ${ }^{\mathrm{TM}}$ controls.

Keywords: Surgery, plastic/trends; Composite resins/therapeutic use; Biocompatible materials/therapeutic use; Prosthe- ses and Implants; Inflammation; Tissue adhesives; Randomized Controlled Trial [Publication Type]; Rabbits/surgery; Comparative study

\section{REFERÊNCIAS}

1. Park JB. Biomaterials: an introduction. New York: Plenum Press; 1979.

2. Sclafani AP, Romo T. $3^{\text {rd }}$ Biology and facial implants. Facial Plast Surg. 2000; 16(1):3-6.

3. Ratner BD, Hoffman AS, Schoen FJ, Lemons JE. Biomaterials science: an introduction to materials in medicine. San Diego: Academic Press; 1996.

4. Williams DF, editor. Medical and dental materials. New York: VCH; 1992.

5. Ousterhout DK, Stelnicki EJ. Plastic surgery's plastics. Clin Plastic Surg. 1996;23(1):183-90.

6. Bonfield W, Grynpas MD, Tully AE, Bowman J, Abram J. Hydroxyapatite reinforced polyethylene - a mechanically compatible implant material for bone replacement. Biomaterials. 1981;2(3):185-6.

7. Argwal BD, Broutman LJ. Analysis and performance of fiber composites. 2nd ed. New York: John Wiley \& Sons; 1990.

8. Olmo N, Martín AI, Salinas AJ, Turnay J, Vallet-Regí M, Lizarbe MA. Bioactive sol-gel glasses with and without a hydroxycarbonate apatite layer as substrates for osteoblast cell adhesion and proliferation. Biomaterials. 2003; 24(20):3383-93.

9. Rubin PA, Popham JK, Bilyk JR, Shore JW. Comparison of fibrovascular ingrowth into hydroxyapatite and porous polyethylene orbital implants. Ophthal Plast Reconstr Surg. 1994;10(2):96-103.

10. Rossa R. Polietileno poroso: avaliação das reações teciduais nas inclusões subcutâneas [tese]. São Paulo: Faculdade de Odontologia da Universidade de São Paulo; 1999.

11. Resende U. Desenvolvimento de compósitos de matriz polimérica com propriedades e bioreatividade controladas para aplicação em plástica ocular [tese]. Belo Horizonte: Universidade Federal de Minas Gerais, Escola de Engenharia; 2002.

12. Goodman SB, Fornasier VL, Lee J, Kei J. The histological effects of the implantation of different sizes of polyethylene particles in the rabbit tibia. J Biomed Mater Res. 1990;24(4):517-24.

13. Wang M. Developing bioactive composite materials for tissue replacement. Biomaterials. 2003;24(13):2133-51.

14. Hench LL. Biochemical processing of materials: a review. In: Cheetham AK, Brinker CJ, MeCartney ML. Better ceramics through chemistry. VI Symposium Materials Research Society; 1994 April 4-8; San Francisco. Proceedings. San Francisco: Material Research Society; 1994. p.993-1004.

15. Kokubo T. Bioactive glass ceramics: properties and applications. Biomaterials. 1991;12(2):155-63

16. Geist CE, Stracher MA, Grove Jr AS. Orbital augmentation by hydroxyapatitebased composites. A rabbit study and comparative analysis. Ophthal Plast Reconstr Surg. 1991;7(1):8-22.

17. Hsu WC, Green GP, Spilker MH, Rubin PA. Primary placement of titanium motility post in a porous polyethylene orbital implant: animal model with quantitative assessment of fibrovascular ingrowth and vascular density. Ophthal Plast Reconstr Surg. 2000;16(5):370-9.

18. Morton AD, Nelson C, Ikada Y, Elner VM. Porous polyethylene as a spacer graft in the treatment of lower eyelid retraction. Ophthal Plast Reconstr Surg. 2000;16(2):146-55.

19. Laaksovirta S, Laurila M, Isotalo T, Valimaa T, Tammela TL, Tormala P, et al. Rabbit muscle and urethral in situ biocompatibility properties of the selfreinforced L-lactide-glycolic acid copolymer 80: 20 spiral stent. J Urol. 2002; 167(3):1527-31.

20. Maas CS, Merwin GE, Wilson J, Frey MD, Maves MD. Comparison of biomaterials for facial bone augmentation. Arch Otolaryngol Head Neck Surg. 1990; 116(5):551-6.

21. Hench LL, Paschall HA. Direct chemical bond of bioactive glass-ceramic materials to bone and muscle. J Biomed Mater Res. 1973;7(3):25-42.

22. Wilson J, Noletti D. Bonding of soft tissues to Bioglass ${ }^{\circledast}$. In: Yamamuro T, Hench LL, Wilson J, editors. CRC Handbook of bioactive ceramics. Calcium phosphate and hyrdoxylapatite ceramics. Boca Raton: CRC Press; 1990. v.2. p. 213-35. 